\title{
On studying ageism in long-term care: A systematic review of the literature
}

\author{
Dr. José Manuel Sousa de São José a* $^{*}$ \\ Dr. Carla Alexandra Filipe Amado ${ }^{\mathrm{b}}$ \\ ${ }^{\text {a }}$ Faculty of Economics, University of Algarve and CIEO \\ Campus de Gambelas \\ 8005-139 Faro, Portugal
}

Email: jsjose@ualg.pt, Telephone: +351289 817571, Fax: +351 289800064

${ }^{\mathrm{b}}$ Faculty of Economics, University of Algarve and CEFAGE-UE

Campus de Gambelas

8005-139 Faro, Portugal

Email: camado@ualg.pt, Telephone: +351 289 817571, Fax: +351 289800064

* Corresponding author 


\begin{abstract}
Background: Ageism in long-term care is pervasive, but it is not easy to define ageism, to identify it and to fight it in practice. These difficulties could be overcome if we develop research capable to conceptualize, detect, measure and understand the multidimensionality and complexity of ageism. Nevertheless, to achieve this it is fundamental to know how ageism in long-term care has been previously studied. Methods: This article systematically reviews studies on ageism in long-term care services published before October 2015 and indexed in Web of Science, PubMed and Social Care Online electronic databases. Electronic searches were complemented with visual scanning of reference lists and hand searching of leading journals in the field of gerontology. Four specific review questions were addressed: Which analytical angles (aetiology, prevalence, manifestations, consequences and interventions) have been explored? Which theories and concepts have been mobilized? Which methods have been employed? Which variants of ageism have been covered? Results: the consequences of ageism and interventions to tackle ageism are analytical angles that have been neglected in previous studies; the vast majority of these studies are under-theorized and poorly conceptualized; concerning research settings, there has been a negligence of nonresidential facilities; the administered scales of ageism use homogenizing terms and do not measure 'sub-types of ageism'; the variants of implicit ageism and self-ageism have been under-explored. Conclusions: research on ageism in long-term care services is scarce but important. Much has been done but much remains to be done. An agenda for future research is presented and discussed.
\end{abstract}

Keywords: Ageism; Age-discrimination; Long-term care; Systematic review 


\section{Introduction}

Ageism is reflected in negative or positive stereotypes, as well as in prejudice or discrimination against (or to the benefit of) older people because of their age (Iversen et al., 2009). It is a pervasive phenomenon that is found in several domains (Palmore, 2001; North and Fiske, 2012), even in those settings which provide care for older people, such as long-term care (LTC) and healthcare (Kane and Kane, 2005; Bowers et al., 2009). Ageism can have serious implications for well-being in that it negatively affects the quality of services (Nelson, 2005). There is also evidence that it produces a deterioration of sense of self-worth (McHugh, 2003), as well as a decline in memory and cognitive performance of the 'victims' (Lamont et al., 2015).

In Europe, perceived age-based discrimination is more prevalent than perceived sex and ethnicity based discrimination (Ayalon, 2014). Despite it being 'the ultimate prejudice, the last discrimination, and the cruellest rejection' (Angus and Reeve, 2006: 139), ageism has been less researched than the other two 'isms' (Nelson, 2005; North and Fiske, 2012). However, this is changing (Abrams et al., 2015).

This article reviews how research on ageism in LTC has been conducted, looking at theories and concepts, as well as to research methods. Thus, we focus on the 'how' rather than the 'what', i.e. the findings/results (please, see the following section for more details). Based on the results of this review, we present several recommendations for future research.

It is important to know how research on ageism in LTC has been conducted for two main reasons. First, a critical analysis of the advances and limitations of past research allows 
extending the research to domains not yet or under-explored, as well as developing research of higher quality. Second, enhancing the quality of empirical research is an essential condition for developing more effective intervention designs (Carolan et al., 2015). A research report on health and social care institutions in England (Roberts et al., 2002) reveals that senior managers see age discrimination as endemic in the local services but, at the same time, they feel it is difficult to deal with it given that it is not easy to define, identify and fight in practice. A critical overview of the way research on ageism in LTC has been conducted offers an opportunity to better conceptualize, detect and measure the manifestations and the prevalence of the phenomenon and, consequently, to strengthen the capacity of conceiving effective interventions to prevent it.

We follow the OECD definition of LTC: 'Long-term care is a range of services required by persons with a reduced degree of functional capacity, physical or cognitive, and who are consequently dependent for an extended period of time ${ }^{1}$ on help with basic activities of daily living (ADL), such as bathing, dressing, eating, getting in and out of bed or chair, moving around and using the bathroom. This is frequently provided in combination with basic medical services such as help with wound dressing, pain management, medication, health monitoring, prevention, rehabilitation or services of palliative care. Long-term care services also include lower-level care related to help with instrumental activities of daily living (IADL), such as help with housework, meals, shopping and transportation. Longterm care can be received in institutions or at home' (OECD, 2008: 33).

\footnotetext{
${ }^{1}$ This definition of LTC does not operationalize 'extended period of time'. However, evidence from the United States of America tells us that the average length of stay in a long-term care facility is 2.4 years (Martin and Ancoli-Israel, 2008).
} 
In another OECD publication (OECD, 2011a) it is stressed that LTC can be provided by ‘(...) family, friends and lower-skilled caregivers or nurses’ (OECD, 2011a: 39). Finally, LTC can be provided by different sectors, such as the state, the market, the voluntary/third sector and the family.

This review will focus on care services, i.e. on care activities that imply helping with activities of daily living (ADL) or instrumental activities of daily living (IADL) or some basic medical needs.

We focus on ageism in LTC for several reasons. First, it is a significantly growing sector. In 2008 , on average, $2.3 \%$ of the population in countries in the Organisation for Economic Co-operation and Development (OECD) was using formal LTC services (OECD, 2011a). An increase of this percentage is expected in the future due to population ageing and the expansion of disability/disease trends, especially among those aged 80 years and older (Lafortune and Balestat, 2007; OECD/European Union, 2013). Second, the users of LTC services tend to be vulnerable, as the majority of them have difficulties in carrying out activities of daily living (OECD, 2011b). The most vulnerable LTC users are at high risk of becoming victims of ageist attitudes and practices (Band-Winterstein, 2013). Finally, LTC workers frequently have low qualifications, low wages (Bettio and Verashchagina, 2010; OECD, 2011a), and low self-esteem (National Health Service, 2013). Low qualification is associated with higher levels of ageist attitudes and stereotypes (Reyna et al., 2007; Wells et al., 2004). 


\section{Review questions}

Four specific review questions are considered: Which analytical angles have been explored? Which theories and concepts of ageism have been used? Which methods have been employed? Which variants of ageism have been covered? In what concerns the first question, we examine which of the following analytical angles are explored in each study: aetiology, prevalence, manifestations, consequences and interventions. With respect to the second question, we identify the theories and conceptual definitions of ageism used by each study, analyzing in particular the number of components of each definition (a clarification of what we mean by components is offered in the next section). In relation to the third question, we look at the following aspects: LTC settings/services, study participants, sampling and data collection. With the last question we examine which variants of ageism have been covered by the reviewed studies, paying particular attention to those not covered or under-covered (a clarification of what we mean by variants is offered in the next section).

\section{Conceptual framework}

Iversen et al. (2009) argue that there has been a lack of consensus on what constitutes ageism. To overcome this, they proposed the following definition of the phenomenon:

'Ageism is defined as negative or positive stereotypes, prejudice and/or discrimination against (or to the advantage of ) elderly people on the basis of their 
chronological age or on the basis of a perception of them as being 'old' or 'elderly'. Ageism can be implicit or explicit and can be expressed on a micro-, meso- or macro-level' (Iversen et al., 2009: 12).

Iversen et al. (2009) established, on the basis of their definition, four dimensions and the components within each dimension: a) the three classic components (cognitivestereotypes, affective-prejudice, behavioral-discrimination); b) the positive/negative aspect (positive ageism, negative ageism); c) the conscious/unconscious aspect (explicit ageism, implicit ageism); and d) the typological division of levels (micro-level ageism, meso-level ageism, macro-level ageism). Subsequently, the authors combined the four dimensions and produced a conceptual framework with 20 variants of ageism.

The definition of ageism proposed by Iversen et al. (2009) is, to our best knowledge, the most comprehensive definition available, as it includes several dimensions and components. However, we agree with Snellman (2016) when he argues that the definition proposed by Iversen and colleagues does not foresee the possibility of young people being a target of ageism, and does not solve the 'us-them distinction', i.e. the distinction between 'us' and 'older people'. The use of words such as 'elderly', 'their' and 'them' in that definition is an indicator that this distinction was not overcome. In our viewpoint, the definition provided by Iversen and colleagues has another shortcoming: it omits 'selfageism', as designated by Bodner et al. (2011). Self-ageism refers to stereotypes and attitudes towards people of one's own age or towards oneself, a phenomenon practiced by all human beings (Levy and Banaji, 2002; Levy, 2003). In order to overcome the aforementioned limitations, we propose the following adaptation of the definition of ageism authored by Iversen et al. (2009): 
Ageism is defined as negative or positive stereotypes, prejudice and/or discrimination against (or to the advantage of) us on the basis of our chronological age or on the basis of a perception of us as being 'old', 'too old', 'young' or 'too young'. Ageism can be self-directed or other-directed, implicit or explicit and can be expressed on a micro, meso or macro-level. ${ }^{2}$

As a consequence of our proposal of introducing the new dimension 'self-directed/otherdirected' with its two components, namely 'self-directed ageism' and 'other-directed ageism' (including ageism from ego to other and vice versa), the conceptual framework with 20 variants of ageism proposed by Iversen et al. (2009) has now 32 variants (see Table 4).

In what concerns the micro-level, the cognitive component refers to what we think about different age groups, the affective component to what we feel about different age groups and the behavioral component to how we behave towards different age groups (Iversen et al., 2009; Abrams et al., 2015). Each of these three components may be self-directed (directed towards people of one's own age or towards oneself) or other-directed (directed from a person to persons of other age groups or vice versa).

In relation to the meso-level, the framework proposed by Iversen et al. (2009) refers only to social networks. However, we opted to follow the broader theoretical proposal of Turner (2005) of integrating micro and macro analysis in the domain of social sciences.

\footnotetext{
${ }^{2}$ Based on this definition, the processes of searching and selecting relevant studies were conducted without any restriction regarding the age of the users of LTC services. However, all the studies selected for review are focused on older adults.
} 
At the meso level of reality, Turner (2005) identifies two structures, 'corporate' units and 'categoric' units. A corporate unit is '(...) a structure and its related culture organized to pursue goals or ends (for example, group, community, bureaucracy)', whilst a categoric unit is '(...) a social category which makes a difference in terms of how people act and are treated by others (for example, gender, ethnicity, age, social class)' (Turner, 2005: 412).

In what concerns the macro-level, ageism in institutional systems accounts for ageism in domains, such as public policy, education and health, and their respective cultures. Iversen et al. (2009) implicitly recognize that the cognitive, affective and behavioral components are also found at the meso and macro levels of reality, but they do not include them in their conceptual framework with 20 variants of ageism. We also do not introduce them in our adaptation in order to avoid an excessive fragmentation of the framework. However, in Tables S2 and S3 (supporting material) we clarify which of the three components (cognitive, affective and behavioral) are present at the meso-level (corporate and categoric units) and macro-level (institutional systems).

Iversen et al. (2009) distinguish between explicit and implicit ageism and between negative and positive ageism. First, whilst the explicit component refers to ageist beliefs, feelings and behavior which are consciously initiated, the implicit component refers to the ageist beliefs, feelings and behavior which are automatically initiated without conscious awareness. Second, negative ageism refers to stereotypes, prejudices and discrimination in disfavor of older people. On the contrary, positive ageism refers to stereotypes, prejudices and discrimination in favor of older people. 
This conceptual framework will be essential to analyze which variants have been covered by the reviewed studies.

\section{Methods}

This systematic review follows the guidelines by the Center for Reviews and Dissemination (CRD) at the University of York (CRD 2009) and the Preferred Reporting Items for Systematic Reviews and Meta-Analyses (PRISMA) (Moher et al., 2009).

\section{Inclusion and exclusion criteria}

We included studies reported in English, French, Spanish and Portuguese, as these are the languages that the authors are able to read. Studies reported in other languages were excluded. Studies which did not focus on ageism, which did not focus on LTC, and those which focused on LTC in terms of cash benefits and other types of benefits beyond care services were excluded. This criterion is justified by the review questions and the concept of LTC adopted in this review. In addition, only studies based on empirical research were included. Theoretical studies, opinion papers, policy documents and literature reviews were excluded (however, the reference lists from literature reviews were visually scanned with the aim of finding relevant studies). This criterion is also justified by the review questions. Finally, we only included articles published in peer reviewed scientific journals, scientific books and book chapters, as we only intend to review empirical 
research submitted to peer reviewing. Studies published before October, 2015, were reviewed.

\section{Search strategy}

Electronic databases: Web of Science, PubMed and Social Care Online, were searched to identify relevant publications. Different combinations of keywords were used to search in these electronic databases:

- ('ageism' or 'age discrimination') AND ('long-term care' or 'long term care' or 'social care' or 'home care' or 'day care center' or 'day care centre' or 'residential care' or 'nursing home' or 'care home' or 'assisted living' or ‘community care' or 'social services' or 'respite care' or 'continuing care retirement communities').

The specific keywords and other specifications used in each database are provided in Box S1 (supporting material).

Searches in electronic databases were combined with visually scanning reference lists from relevant publications and literature reviews, research reports and other publications. A hand search of leading journals on Gerontology and Social Care, including, the European Journal of Ageing, the International Psychogeriatrics, the Health \& Social Care in the Community, the Journal of Aging Studies, and The Gerontologist was also undertaken. 
Selection of publications

The selection of publications was undertaken using the PRISMA flow diagram (Moher et al., 2009). Figure 1 presents the stages of the selection process. All stages were conducted independently by the authors and disagreements were resolved through a consensus.

<please insert Fig. 1 about here>

\section{Data extraction}

Data were extracted using a data extraction form. A preliminary version of this form was pilot-tested in four randomly selected publications and the form was refined accordingly. The data extraction form includes the following items: author and date, research objectives, theoretical framework, study design (qualitative vs. quantitative), LTC services/settings, study participants (sampling methods; sample size), research methods (methods used to collect and analyze data), themes indicating ageism (qualitative studies) and operationalization of ageism (quantitative studies), and quality rating (quality appraisal of the publications).

The quality appraisal was also carried out using a form. A preliminary version of the form was pilot-tested in four randomly selected included publications, which revealed the need to refine it slightly. Box S2 (supporting material) provides the final version of the quality appraisal form used to evaluate the publications. It includes the following items: background/rationale of the study; objectives; study design; sampling; conceptual definition of ageism; themes indicating ageism/operationalization of ageism; data 
collection and data analysis; results/findings and discussion; quality of the results/findings and limitations. The quality was assessed chiefly in relation to reporting (to what extent the aforementioned items were covered in each publication). The overall quality rating attributed to each paper is qualitative (e.g.: meets 14 items out of 16).

The process of data extraction (including the quality appraisal) was conducted by the authors of this review (working independently) and any disagreements were resolved through a consensus.

\section{Data synthesis}

Data were synthesized by using the following approaches: 'narrative synthesis' (Popay et al., 2006) with respect to the first three review questions, and 'narrative synthesis' and 'thematic synthesis' (Thomas and Harden, 2008) with respect to the fourth review question.

Narrative synthesis '(...) refers to an approach to the systematic review and synthesis of findings from multiple studies that relies primarily on the use of words and text to summarize and explain the findings of the synthesis. Whilst narrative synthesis can involve the manipulation of statistical data, the defining characteristic is that it adopts a textual approach to the process of synthesis to 'tell the story' of the findings from the included studies.' (Popay et al., 2006: 5). In this article, narrative synthesis was supported by organizing and presenting data in tabular form (Popay et al., 2006). 
'Thematic synthesis' is based on three stages. In the first stage, the aim is to code the data extracted. This initial coding produces 'free codes'. In the second stage, these codes are grouped into 'descriptive' themes. In the third stage, the aim is to aggregate 'descriptive' themes into 'analytical themes' (higher order themes created by the reviewers). This synthesis was carried out with the help of the software NVivo 9.

\section{A brief overview of the included studies}

As shown in Figure 1, we screened a total of 143 articles. Of these, 20 articles were selected for inclusion in this review.

In general, the research on ageism in LTC services is relatively recent, as 14 of the reviewed studies were published between 2011 and 2015, with the remaining six published between 2000 and 2010. The research aims of the reviewed studies are highly diverse, ranging from examining the evidence of age discrimination in care practices to understanding the experiences of older women living in LTC with urinary incontinence (see Table S1, supporting material). In the great majority of the studies ageism is a central topic, but there are some studies in which ageism is a secondary topic, given that it is conceived as a predictor of, or as a factor associated with other phenomenon, namely: elder neglect (Band-Winterstein, 2013), pain assessment (Natan et al., 2013), utilization of care services (Petersen and Warburton, 2012) and older people's autonomy (Taverna et al., 2014). There are also two studies which do not focus primarily on ageism but where ageism emerged as a theme or subtheme during the process of qualitative data analysis (MacDonald and Butler, 2007; Doyle, 2014). Most studies were conducted in North America (Canada and United States of America), and Australia. The remaining studies 
were conducted in the United Kingdom (England and Scotland), Israel and Sweden. It is important to stress that all studies met 13 or more items out of 16 , meaning that all studies have a high rating with respect to reporting. This precluded a comparison of the results according to the quality rating of the studies.

\section{Results}

Which analytical angles have been explored?

All studies explored the manifestation of ageism (see Table 1). The majority also explored other analytical angles. The aetiology and the prevalence of ageism are the second most explored angles. Only two studies addressed the consequences of ageism and none addressed interventions concerning ageism in LTC.

<please insert Table 1 about here>

Which theories and concepts have been used?

The reviewed studies used diverse theoretical frameworks. This might be a result of the diversity of research objectives pursued by the studies. Table 2 presents a synthesis regarding the number of studies that used theories and conceptual definitions of ageism. As it can be verified from this table, none of the studies includes theories that specifically focused on ageism in their theoretical frameworks. Theories used in some of the studies, include Goffman's perspectives on stigma and depersonalization in institutions, Age Stratification Theories, Foucault's perspectives on power, Normative Ethical Theories, 
and Communication Accommodation Theory. Two theories related to ageism, the Terror Management Theory and the Social Identity Theory, are mentioned briefly in the discussion sections of two studies. ${ }^{3}$

<please insert Table 2 about here>

The concept of ageism is defined in all the studies reviewed, with the exception of one study. However, in five studies, ageism is defined only implicitly, although it is a central topic in these studies. Applying the framework of 32 variants of ageism described earlier, nearly half the studies use conceptual definitions of ageism with a low number of components. These definitions are clearly dominated by those proposed by Butler (1969, 1975), especially by the 1975 definition that is the classic definition of ageism (Iversen et al., 2009). It includes five components of ageism: cognitive, behavioral, other-directed, explicit, negative. Another set of nine studies use conceptual definitions of ageism with a moderate number of components, including the definitions proposed by Cuddy et al. (2005), Greenberg et al. (2002); Hagestad and Uhlenberg (2005); Levy and Banaji (2002) and Palmore (1999). One study, in which ageism is not a central topic, uses a conceptual definition of ageism with 11 or more components, namely the definition proposed by Iversen et al. (2009). ${ }^{4}$

\footnotetext{
${ }^{3}$ For a brief review of theories of ageism, please refer to North and Fiske (2012, 2013).

${ }^{4}$ For a review of conceptual definitions of ageism, please refer to Iversen et al. (2009).
} 
Which methods have been employed?

Table 3 provides a synthesis of the methodological strategies used in the reviewed studies. Most studies adopted a qualitative approach (13 studies) with predominance of ethnography and phenomenology. Among the remaining studies, five adopted a quantitative approach and two a mixed approach (combining quantitative and qualitative methods).

The vast majority of qualitative studies selected exclusively residential services to collect data (i.e. services which include accommodation/housing for older people who cannot live on their own, such as independent living, assisted living, nursing home, sheltered housing, and so on). Only two studies selected non-residential services (i.e. services which do not include accommodation, such as home care) and the remaining one selected mixed settings (residential and non-residential). Three of the five quantitative studies selected exclusively residential services and two selected mixed settings. The mixed studies selected solely residential services. Therefore, the great majority of the studies focus on residential services (see Table 3 ).

Four qualitative studies relied exclusively on older persons, two included exclusively staff members and one older persons' relatives. Most quantitative studies relied on staff members, with only one study including different types of participants. The two mixed studies collected data from a mixed group of participants (see Table 3). 
Apart from one study which did not use sampling (strategies to systematically select research participants), as it selected the entire target population, and five studies which did not explicitly identify the sampling methods, the remaining studies used nonprobability sampling. All samples, regardless of the study design, are heterogeneous. This heterogeneity relates to the basic sociodemographic variables (sex, age, level of schooling, etc.) and, in some cases, also relates to ethnicity, duration of residency, type of care facility, care profession, and duration of work with older people and in the facility.

<please insert Table 3 about here>

The qualitative studies used a mixture of methods to collect data (7 studies; mainly interviews and participant observations) or exclusively interviews (6 studies). In turn, the quantitative studies used exclusively questionnaires and the mixed studies used a mixture of methods. In this respect, it is possible to verify that most of the studies opted to use a single method to collect data (see Table 3).

All quantitative studies used validated scales of ageism to collect data, namely the Fraboni Scale of Ageism (Fraboni et al., 1990), the Thompson List of Ageist Assumptions (Thompson, 2006), the Attitudes Towards Older People Scale (Kogan, 1961), the Aging Semantic Differential Scale (Rosencranz and McNevin, 1969), the Facts on Aging Quiz (Palmore, 1977, 1998) and the Reactions on Ageing Questionnaire (Gething, 1994). Most of these scales are organized by dimensions/factors (Fraboni, Aging Semantic Diferential and Reactions on Aging) ${ }^{5}$ and are composed by a set of statements with a Likert scale to measure the level of agreement with each statement. The statements address older people

\footnotetext{
${ }^{5}$ The definitions of the scales' dimensions/factors are presented in the footnotes to Table S3 (supporting material).
} 
in general and not older people who receive LTC services. Here are some examples of statements which convey negative stereotypes about older people: 'Many old people just live in the past' (Fraboni Scale); 'The majority of aged live alone' (Facts on Aging Quiz); 'Most old people are irritable, grouchy, and unpleasant' (Attitudes Toward Older People Scale). Expressions such as 'old people', 'elderly people' and 'the aged' appear in all the scales, with the exception of the Aging Semantic Differential Scale. These expressions display 'older people' as a homogeneous group.

Finally, the qualitative studies used several methods of data analysis, with predominance for ethnography, phenomenology and thematic analysis, whereas the quantitative studies used several methods of statistical analysis, such as descriptive statistics, statistical inference, factor analysis and regression analysis. The mixed studies combined thematic analysis with descriptive statistics.

\section{Which variants of ageism have been covered?}

We identified a list of themes and subthemes of ageism, as reported by the qualitative studies (and the qualitative parts of the mixed studies), and pointed to the components of ageism covered by each theme (see Table S2, supporting material). Most themes (Providing care in a rigid and rushed manner; Requesting older adults to undertake childish activities; Not giving an older person enough privacy; Giving excessive medication and not reviewing it often enough; Respecting older people because of their age; Advertising older people as ageless for business purposes) are 'descriptive themes'. The remaining themes are 'analytical themes' (higher order themes) in that they were created by the authors to aggregate 'descriptive themes'. 
We also identified the operationalization of ageism in quantitative studies (and the quantitative parts in mixed-methods studies). As the operationalization of ageism is reflected in the instruments which were used to collect data, in Table S3 (supporting material) we describe the factors/dimensions of these instruments, the factors/dimensions which were included in each study and the components of ageism covered.

All scales measure explicit ageism, i.e. conscious ageism, rather than implicit ageism. ${ }^{6}$ Second, all scales, with the exception of the Aging Semantic Differential Scale and the Reactions on Ageing Questionnaire, have at least one statement that measures attitudes towards discrimination at the meso or macro level of reality, such as discrimination in social networks, healthcare, leisure, political participation, and son on (e.g.: 'There should be special clubs set aside within sports facilities so that old people can compete at their own level' - Fraboni Scale of Ageism).

Table 4 offers a synthesis of the variants of ageism that have been covered in the reviewed studies. 'Cognitive, other-directed, explicit, negative' statements represent the most common variant covered. The second most covered variant of ageism is 'corporate and categoric, explicit, negative'. Next is the variant 'behavioral, other-directed, explicit, negative'. Despite the significant coverage of these three variants of ageism, the majority of them are not covered by any study (17 variants) and some variants are only covered by one or two studies. Both self-directed and implicit ageism were neglected by research.

<please insert Table 4 about here>

\footnotetext{
${ }^{6}$ According to Levy and Banaji (2002) the most commonly used instruments to measure implicit ageism are the 'Implicit Association Test' and 'Priming'.
} 


\section{Discussion}

The objective of this systematic review was to gather a comprehensive and accurate picture of past research on ageism in LTC. Four specific review questions were formulated: Which analytical angles have been explored? Which theories and concepts have been used? Which methods have been employed? Which variants of ageism have been covered?

Regarding the first question, we can say that we already have a reasonable body of evidence on the manifestation of ageism in LTC, as all studies explored this angle of analysis. This evidence is important not only for researchers but also for professionals and policy makers. In what respects to professionals and policy makers, the evidence on the manifestation of ageism puts them in a better position to fight ageism in practice. However, the remaining angles considered in this review received less attention, especially the consequences of ageism that received minimal attention, and interventions to reduce ageism that did not receive any attention. Hence, on the one hand we have a reasonable knowledge about the manifestation of ageism in LTC but, on the other hand, we do not know which interventions are effective to prevent and fight the forms of ageism that we have identified.

As for the second review question, none of the reviewed studies included a theory that primarily focused on ageism. Although some of the mobilized theories have clear links to ageism, such as the Goffman's perspectives on stigma and depersonalization in institutions, the absence of theories specifically focused on ageism prevents the theoretical development of this particular field of inquiry. It is important to note that the 
majority of the studies adopted qualitative approaches, which tend not to explicitly adhere to a theoretical framework. However, a dialogue with theories of ageism, even in strongly inductive qualitative studies, would have enriched these studies (e.g. Alley et al., 2010). Incorporating a theoretical framework in research is important because it helps to define research questions, to explain research findings/results and to inform interventions (Alley et al., 2010). As Ferraro (2009: 75) argues, research without theory, and we would say, research on ageism without theories on ageism, may lead to 'a science of the commonplace', or at least, in our opinion, a science that does not reach its full potential. Nevertheless, Bengtson and colleagues (2009) argue that research on ageing, in which we would also include research on ageism, is 'data-rich but theory-poor', meaning that theories do not abound in this particular field of inquiry.

Despite the fact that none of the reviewed studies has used theories of ageism, almost all offered a definition of ageism, although in some cases only implicitly. Nevertheless, nearly half of the studies use narrow concepts of ageism (i.e. concepts with a low number of components of ageism) or do not use any concept of ageism, in addition to not mobilizing theories specifically related with ageism. This means that ageism was under-theorized and poorly conceptualized in these studies. In the other half of the studies, ageism is also under-theorized but better conceptualized, given that they use broader conceptual definitions of ageism. We acknowledge that concepts are normally chosen according to the aims of the studies, and that in some cases, such as when we have a concise research question and we want to test a restricted set of hypotheses, using narrow concepts rather than broad concepts can be appropriate. However, when we intend to undertake an exploratory study, as was the case of the reviewed qualitative studies, using a narrow definition of the phenomenon under study can compromise the ability to iteratively 
capture its multidimensionality and complexity. For example, the definition proposed by Butler (1975), which is the classic definition but still widely used (Iversen et al., 2009) is, according to some authors (e.g., Iversen et al., 2009; North and Fiske, 2013) no longer adequate for capturing the complexity of the phenomenon.

The majority of the studies were conducted in residential services (only one study was conducted in the elders' homes). This means that we already have a significant body of evidence on ageism in residential facilities. However, considering the diversity of settings currently found in LTC services and the trend towards community care, especially home care, found in many parts of the world (Huber et al., 2009), a special attention should be given to other LTC services in the future. In the current state of research, we are not able to clarify whether ageism in non-residential facilities has the same features (e.g. manifestation, prevalence, etc.) as ageism in residential facilities. In addition, the perspectives of those who are the target of ageism, namely, older adults, have been somewhat neglected. This may implicate an underestimation of the prevalence of ageism, given that the most subtle forms of prejudice are more readily detected by the target rather than by the holder of prejudice (Abrams et al., 2015).

One of the mixed-methods studies used validated scales of ageism and the quantitative studies used only these scales to collect data. Considering the aims of these studies, the scales that were used are appropriate. However, these scales have limitations, not fully recognized by the authors of these studies (with the exception of very few cases). These scales are self-reporting techniques, and therefore prone to social desirability effects, which may involve an underestimation of the prevalence of ageism (Lagacé et al., 2012; Natan et al., 2013). In addition, almost all the scales include statements which consist of 
homogenizing expressions, such as 'old people', 'elderly people' and 'the aged.' These kinds of expressions persist in the recent revision of the Fraboni Scale (Rupp et al., 2005). This is problematic because, as North and Fiske (2013: 38) argue, 'Despite lay beliefs that older people are relatively uniform in appearance, attitudes, and health, the older population is actually one of the most diverse'. In the 1970s, Neugarten (1974) proposed a distinction between the 'young-old' and the 'old-old'. Later, Laslett (1994) proposed a distinction between the 'third age' and the 'fourth age'. Furthermore, Gilleard and Higgs (2011) suggested that the 'destandardisation of later life' questions the importance of chronological age. Therefore, using homogenizing expressions creates a serious risk of multiple interpretations on the part of the respondents and is a potential source of bias. It is also important to note that the scales reviewed are not context-specific, i.e. they focus on older people in general and not on older people in specific contexts, such as LTC services. A scale devoted to ageism in LTC likely would have yielded different results.

Finally, we found that the studies have covered a small number of variants of ageism. This is not entirely surprising, given that studies focused on ageism in LTC do not abound. Some variants have been sufficiently covered, particularly the variant 'Cognitive, otherdirected, explicit, negative', but there is still important 'ground to explore'. It is important to underline that the variants which include implicit ageism and self-directed ageism have been neglected. The importance of the implicit component of ageism is well explained by Levy and Banaji (2002). These authors claim that all humans, regardless of their age, participate in the process of implicit ageism, and that ' $(\ldots)$ one of the most insidious aspects of ageism is that it can operate without conscious awareness, control, or intention to harm' (Levy and Banaji, 2002: 50). Implicit ageism is the root of ageist practices (Levy and Banaji, 2002), such as the ageist language used by LTC workers (Lagacé et al., 2011, 
2012). Iversen et al. (2009: 16) argue that when a physician has a rigid schedule and scarce time, 'implicit ageism may result in even less time for the elderly patients combined with a tendency to ascribe their complaints to old age'. We hypothesize that this can also happen in LTC settings. The self-direct component of ageism, i.e. selfageism, is commonly implicit (unconscious) and therefore, can be particularly harmful (Levy and Banaji 2002). Several studies have demonstrated that implicit self-ageism may have a negative impact on the older persons' cognition, behavior and health (e.g. Palmore, 1999; Levy and Banaji, 2002). Under-exploration of implicit ageism and self-directed ageism implies that we still have an incomplete picture of the prevalence and manifestations of ageism in LTC.

Recommendations for future research

Based on the review outlined above, we present recommendations for future research on ageism in LTC. Some of these recommendations can also be applied in health care settings in general.

Our first recommendation is to develop studies that explore the consequences of ageism and interventions to tackle ageism. Studies on interventions to tackle ageism are particularly needed, otherwise we will have little chance to effectively prevent or combat ageism in LTC.

We also recommend that future studies rely more heavily on theories of ageism or that, at least, establish a dialogue with these theories in order to developed them and/or create 
new ones. Furthermore, we believe that if we want to fight ageism in LTC in an effective manner, then we will need to identify and understand its multiple variants, especially the most subtle ones, such as those which include self-directed ageism and implicit ageism. This can be achieved, amongst other things, by using a comprehensive conceptual definition of ageism, such as the adapted definition that we proposed earlier in the conceptual framework. Even qualitative studies could use the aforementioned adapted definition of ageism, but in a sensitizing way (i.e. in a flexible way) in order to allow the emergence of new variants. If we identify which specific variants of ageism are most prevalent in a certain setting, we are in a better position to develop effective interventions and policies to fight it in practice.

Future studies should also pay more attention to non-residential facilities, especially home care that has grown in popularity in many countries, and to include the perspective of older persons. Potential research questions which deserve further attention, include the following: Does ageism in non-residential care (e.g. home care) have the same features (in terms of aetiology, manifestations, prevalence and consequences) as ageism in residential care? What is the level of ageism perceived by older people in LTC and how do they deal with its different manifestations?

Regarding methods of data collection, we agree with the suggestion made by Pedersen and Mehlsen (2011) that future studies should combine self-reporting techniques with non-self-reporting techniques, such as, participant observation. Other methods such as diaries, a method which has proved effective in capturing the daily lives of older people (Bytheway and Johnson, 2001) or drawings could enrich current knowledge. Scales of ageism will benefit from removing homogenizing terms, such as 'the aged' and 'elderly 
people', and taking into account 'subtypes of ageism' (North and Fiske, 2013), i.e. ageism targeted at different subtypes of older people. The Aging Semantic Differential Scale is a good example in this respect, because it can be used with different age groups.

As argued above, fighting ageism in LTC in an effective way requires paying more attention to its most subtle variants, such as those which include self-directed ageism and implicit ageism. These are some examples of research questions regarding these two kinds of variants: How is implicit ageism manifested in daily practices of care staff? To what extent do older persons refuse to receive certain services, because they think they are too old? Future studies will need to develop new strategies and tools to measure and detect these subtle forms of ageism (Abrams et al., 2015).

We take the opportunity to make a final recommendation. Following the arguments of Calasanti and Slevin (2006), we recommend that future research will explore the intersections between ageism and other forms of oppression, such as those based on gender or ethnicity/race. This will enrich theories and understanding concerning ageism.

\section{Limitations}

Despite its potential contribution, this systematic review has some limitations. First, it is always possible that we may have missed some relevant studies. Second, data extraction involved subjective judgments of the two authors. This was particularly evident in the detection of variants of ageism covered by the scales used in quantitative studies, as some of the statements inserted in the scales are in the border between two components of ageism. Despite our great care in this process, this can be a potential source of bias. 


\section{Concluding remarks}

This review fills a gap by systematically reviewing approaches used for empirically studying ageism in LTC services, and by discussing avenues for future research in this area. We conclude that the research on ageism in LTC services is still scarce but important. Much has been done but much remains to be done. We hope that the recommendations that we have made could be useful to produce further studies in order to capture the multidimensionality and complexity of ageism in LTC.

It is our conviction that research focused on ageism in LTC services and other care settings should continue in order to obtain a better understanding of the phenomenon. This will contribute to preventing and fighting ageism.

\section{Conflict of interest}

None.

\section{Description of authors' roles}

All the stages of the review process had the participation of both authors. 


\section{Acknowledgements}

This paper is funded by National Funds provided by FCT- Foundation for Science and Technology and FEDER/COMPETE (Project UID/SOC/04020/2013; Grant PEstC/EGE/UI4007/2013). This publication is also supported by COST (the acronym for European Cooperation in Science and Technology) IS1402 on ageism.

\section{Supporting Information}

To view supplementary material for this paper, please visit

\section{References}

Abrams, D., Swift, H.J., Lamont, R.A. and Drury, L. (2015). The barriers to and enablers of positive attitudes to ageing and older people, at the societal and individual level. Foresight, Government Office for Science. Kent: University of Kent. Available at: https://www.gov.uk/government/uploads/system/uploads/attachment_data/file/454735/gs-15-15-future$\underline{\text { ageing-attitudes-barriers-enablers-er06.pdf }}$ 
Running title: On studying ageism in long-term care

Alley, D.E., Putney, N.M., Rice, M. and Bengtson, V.L. (2010). The increasing use of theory in social gerontology: 1990-2004. The Journals of Gerontology. Series B, Psychological Sciences and Social Sciences, 65, 583-590. doi: 10.1093/geronb/gbq053.

Angus, J. and Reeve, P. (2006). Ageism: A Threat to "Aging Well" in the 21st Century. Journal of Applied Gerontology, 25, 137. doi: 10.1177/0733464805285745.

Ayalon, L. (2014). Perceived Age, Gender, and Racial/Ethnic Discrimination in Europe: Results from the European Social Survey. Educational Gerontology, 40, 499-517. doi: 10.1080/03601277.2013.845490.

Ayalon, L. (2015). Perceptions of old age and aging in the continuing care retirement community. International Psychogeriatrics, 27, 611-6620. doi: 10.1017/S1041610214002415.

Band-Winterstein, T. (2013). Health Care Provision for Older Persons: The Interplay Between Ageism and Elder Neglect. Journal of Applied Gerontology, XX, 1-15. doi: 10.1177/0733464812475308.

Bengtson, V. L., Gans, D., Pulney, N. M., and Silverstein, M. (2009). Handbook of theories of aging (2 ed.). New York: Springer Publishing Co.

Bettio, F. and Verashchagina, A. (2010). Long-Term Care for the elderly. Provisions and providers in 33 European countries, EU Expert Group on Gender and Employment. Roma: Fondazione G. Brodolini.

Billings, J. (2006). Staff perceptions of ageist practice in the clinical setting: Practice development project. Quality in Ageing and Older Adults, 7, 33 - 45. doi.org/10.1108/14717794200600012.

Bodner, E., Cohen-Fridel, S. and Yaretzky, A. (2011). Sheltered housing or community dwelling: quality of life and ageism among elderly people. International Psychogeriatrics, 23, 1197-1204. doi: $10.1017 / \mathrm{S} 1041610211001025$. 
Running title: On studying ageism in long-term care

Bowers, H., Clark, A., Crosby, G. et al (2009). Older people's vision for long-term care. Executive summary. York: Joseph Rowntree Foundation, Available at: http://www.cpa.org.uk/ltc/older-peoplevision-for-care-full.pdf (accessed on 4 September 2015).

Butler, R.N. (1969). Age-ism: Another form of bigotry. The Gerontologist, 9, 243-246.

Butler, R.N. (1975). Why Survive? Being old in America. New York: Harper and Row.

Bytheway, B. and Johnson, J. (2001). An evaluation of the use of diaries in a study of medication in later life. International Journal of Social Research Methodology, 3, 183-204. doi: $10.1080 / 13645570010029467$.

Calasanti, T.M. and Slevin, K.F. (2006). Age Matters: Realigning Feminist Thinking. New York and London: Routledge.

Carolan, C.M., Smith, A. and Forbat, L. (2015). Conceptualising psychological distress in families in palliative care: Findings from a systematic review. Palliative Medicine, 29, 605-632.

Condelius, A. and Andersson, M. (2015). Exploring access to care among older people in the last phase of life using the behavioural model of healthservices use: a qualitative study from the perspective of the next of kin of older persons who had died in a nursing home. BMC Geriatrics, 15, 138. doi: 10.1186/s12877-015-0126-9.

CRD (2009). Systematic Reviews. CRD's guidance for undertaking reviews in health care. Centre for Reviews and Dissemination. York. Available at: https://www.york.ac.uk/media/crd/Systematic_Reviews.pdf. Accessed 4 September 2015

Cuddy, A., Norton, J.C., Norton, M.I. and Fiske, S.T. (2005). This old stereotype: The pervasiveness and persistence of the elderly stereotype. Journal of Social Issues, 61, 267-285. doi:10.1111/j.15404560.2005.00405.x. 
Running title: On studying ageism in long-term care

Dobbs, D., Eckert, J.K. et al (2008). An Ethnographic Study of Stigma and Ageism in Residential Care or Assisted Living. The Gerontologist, 48, 517-526.

Doyle, S. (2014). The Impact of Power Differentials on the Care Experiences of Older People. Journal of Elder Abuse \& Neglect, 26, 319-332. doi: 10.1080/08946566.2013.875970.

Dunworth, M. and Kirwan, P. (2012). Do nurses and social workers have different values? An exploratory study of the care for older people. Journal of Interprofessional Care, Early Online: 1-6. doi: $10.3109 / 13561820.2011 .645172$.

Ferraro, K.F. (2009). Theory welcome here. The Journals of Gerontology. Series B, Psychological Sciences and Social Science,s 64b, 75-76.

Fraboni, M., Saltstone, R. and Hughes, S. (1990). The Fraboni scale of ageism (FSA): an attempt at a more precise measure of ageism. Canadian Journal on Aging / La Revue Canadienne du Vieillissement, 9, 5556.

Gamliel, T. (2000). The Lobby as an Arena in the Confrontation Between Acceptance and Denial of Old Age. Journal of Aging Studies, 14, 251-271.

Gething, L. (1994). Health professionals' attitudes towards ageing and older people: Preliminary report of the reactions to ageing questionnaire. Australasian Journal on Ageing, 13, 77-81.

Gilleard, C. and Higgs, P. (2011). Ageing Abjection and Embodiment in the Fourth Age. Journal of Aging Studies, 25, 135-142.

Greenberg, J., Schimel, J. and Martens, A. (2002). Ageism: Denying the face of the future. In T.D. Nelson (Ed.) Ageism: stereotyping and prejudice against older persons (pp. 27-48). MIT Press, Cambridge, MA. 
Running title: On studying ageism in long-term care

Hagestad, G.O. and Uhlenberg, P. (2005). The Social Separation of Old and Young: A Root of Ageism. Journal of Social Issues, 61, 343-360. doi:10.1111/j.1540-4560.2005.00409.x.

Hubber, M., Rodrigues, R., Hoffmann, F., Gasior, K. and Marin, B. (2009). Facts and Figures on LongTerm Care. Europe and North America. Vienna: European Centre.

Iversen, T.N., Larsen, L. and Solem, P.E. (2009). A conceptual analysis of Ageism. Nordic Psychology, $61,4-22$.

Kane, R.L. and Kane, R.A. (2005). Ageism in Healthcare and Long-Term Care. Generations, 29, $49-54$.

Kogan, N. (1961). Attitudes towards old people: the development of a scale and examination of correlates. Journal of Abnormal and Social Psychology, 62, 44-54.

Lafortune, G. and Balestat, G. (2007). Trends in Severe Disability Among Elderly People: Assessing the Evidence in 12 OECD Countries and the Future Implications. OECD Health Working Papers, No. 26. Paris: OECD Publishing. Available at: http://dx.doi.org/10.1787/217072070078. Accessed 4 September 2015.

Lagacé, M., Medouar, F., Loock, J. and Davignon, A. (2011). À mots couverts: le regard des aînés et des soignants sur la communication quotidienne et ses manifestations d'âgisme implicite. Canadian Journal on Aging / La Revue Canadienne du Vieillissement, 30, 185-196. doi:10.1017/S0714980811000092.

Lagacé, M., Tanguay, A., Lavallée, M. et al (2012). The silent impact of ageist communication in long term care facilities: Elders' perspectives on quality of life and coping strategies. Journal of Aging Studies, 26, 335-342.

Lamont, R.A., Swift, H.J. and Abrams, D. (2015). A review and meta-analysis of age-based stereotype threat: Negative stereotypes, not facts, do the damage. Psychology and Aging, 31, 180-193. 
Running title: On studying ageism in long-term care

Laslett, P. (1994). The Third Age, The Fourth Age and The Future. Ageing \& Society, 14, 436-447.

Levy, B.R. (2003). Mind matters: cognitive and physical effects of aging self-stereotypes. The Journals of Gerontology. Series B, Psychological Sciences and Social Sciences, 58B, 203-211.

Levy, B.R. and Banaji M.R. (2002). Implicit Ageism. In T.D. Nelson (Ed.) Ageism Stereotyping and prejudice against older persons (pp. 49-75). Cambridge, Massachussetts: MIT Press.

MacDonald, C.D. and Butler, L. (2007). Silent No More Elderly Women's Stories of Living with Urinary Incontinence in Long term Care. Journal of Gerontological Nursing, 33, 14-20.

Martin, J.L. and Ancoli-Israel, S. (2008). Sleep Disturbances in Long-Term Care. Clinical Geriatric Medicine, 24, 39-vi.

McHugh, K.E. (2003). Three faces of ageism: Society, image and place. Ageing \& Society, 23, 165-185.

Moher, D., Liberati, A., Tetzlaff, J. et al (2009). Preferred Reporting Items for Systematic Reviews and

Meta-Analyses: $\quad$ The PRISMA $\quad$ Statement. $\quad$ PLoS http://www.plosmedicine.org/article/fetchObject.action?uri=info:doi/10.1371/journal.pmed.1000097\&rep resentation=PDF. Accessed 4 September 2015.

Natan, M.B., Ataneli, M., Admenko, A. and Noy, R.H. (2013). Nurse assessment of residents' pain in a long-term care facility. International Nursing Review, 60, 251-257.

National Health Service (2013). The Cavendish Review. An Independent Review into Healthcare Assistants and Support Workers in the NHS and social care settings. London: National Health Servive. Available at: https://www.gov.uk/government/uploads/system/uploads/attachment_data/file/236212/Cavendish_Revie W.pdf (accessed 4 September 2015). 
Running title: On studying ageism in long-term care

Nelson, T.D. (2005). Ageism: Prejudice against our feared future self. Journal of Social Issues, 61, 207221.

Neugarten, B. (1974). Age groups in American society and the rise of the young old. The Annals of the American Academy of Political and Social Science, 187-198. The Annals of the American Academy of Political and Social Science, 436-447. doi:10.1017/S0144686X00001677.

North, M.S. and Fiske, S.T. (2012). An Inconvenienced Youth? Ageism and Its Potential Intergenerational Roots. Psychological Bulletin, 138, 982-997.

North, M.S. and Fiske, S.T. (2013). Subtyping Ageism: Policy Issues in Succession and Consumption. Social Issues and Policy Review, 7, 36-57. doi:10.1111/j.1751 2409.2012.01042.x.

OECD (2008). OECD Health Data 2008. Paris: OECD.

OECD (2011a). Help Wanted? Providing and Paying for Long-Term Care. Paris: OECD Publishing. doi:10.1787/9789264097759-en.

OECD (2011b). Health at a Glance 2011: OECD Indicators. Paris: OECD Publishing. Available at: http://dx.doi.org/10.1787/health_glance-2011-en (accessed 4 September 2015).

OECD/European Union (2013). A Good Life in Old Age? Monitoring and Improving Quality in Long-term

Care, OECD Health Policy Studies. Paris: OECD Publishing. Available at: http://dx.doi.org/10.1787/9789264194564-en (accessed 4 September 2015).

Palmore, E.B. (1977). Facts on Aging: A short quiz. The Gerontologist, 17, 315-320.

Palmore, E.B. (1998). The Facts on Aging Quiz. New York: Springer Publishing Company.

Palmore, E.B. (1999). Ageism: Negative and positive. New York: Springer. 
Running title: On studying ageism in long-term care

Palmore, E.B. (2001). The Ageism Survey: First findings. The Gerontologist, 41, 572-575.

Pedersen, A.D. and Mehlsen, M. (2011). Age-Bias in Staff Appraisals of Brain Injury Service Provision? Nordic Psychology, 63, 25-39.

Petersen, M. and Warburton, J. (2012). Residential complexes in Queensland, Australia: a space of segregation and ageism? Ageing \& Society, 32, 60-84. doi:10.1017/S0144686X10001534

Petticrew, M. and Roberts, H. (2006). Systematic Reviews in the Social Sciences. A Practical Guide. Malden: Blackwell Publishing.

Popay, J., Roberts, H., Sowden A. et al (2006). Guidance on the conduct of narrative synthesis in systematic reviews. London: ESRC Research Methods Programme.

Reyna, C., Goodwin, E.J. and Ferrari, J.R. (2007). Older adult stereotypes among care providers in residential care facilities. Journal of Gerontological Nursing, 33, 50-55.

Roberts, E., Robinson, J. and Seymor, L. (2002). Old Habits Die Hard: Tackling age discrimination in health and social care. London: King's Fund.

Rosencranz, H.A. and McNevin, T.E. (1969). A factor analysis of attitudes toward the aged. The Gerontologist, 9, 55-59.

Roth, E.G., Keimig, L., Rubinstein, R.L., Morgan, L., Eckert, J.K., Goldman, S. and Peeples, A.D. (2012). Baby Boomers in an active adult retirement community: comity interrupted. The Gerontologist, 52, 189198. doi: 10.1093/geront/gnr155.

Roth, E.G., Eckert, J.K. and Morgan, L.A. (2015). Stigma and Discontinuity in Multilevel Senior Housing's Continuum of Care. The Gerontologist, 00, 1-10. doi:10.1093/geront/gnv055 
Running title: On studying ageism in long-term care

Rupp, D.E., Vodanovich, S.J. and Credé, M. (2005). The Multidimensional Nature of Ageism: Construct Validity and Group Differences. The Journal of Social Psychology, 145, 335-362.

Snellman, F. (2016). Whose ageism? The reinvigoration and definitions of an elusive concept. Nordic Psychology, 68, 148-159. doi: 10.1080/19012276.2015.1125301.

Taverna, M.V., Nguyen, C, Wright, R et al (2014). Iatro-Compliance: An Unintended Consequence of Excessive Autonomy in Long Term Care Facilities. Journal of Dental Hygiene, 88, 53-60.

Thomas, J. and Harden, A. (2008). Methods for the thematic synthesis of qualitative research in systematic reviews. BMC Medical Research Methodology, 8, 45._doi:10.1186/1471-2288-8-45.

Thompson, N. (2006). Anti-discriminatory practice. Basingstoke: Palgrave Macmillan.

Turner, J.H. (2005). A New Approach for Theoretically Integrating Micro and Macro Analysis. In C. Calhoun, C. Rojek and B.S. Turner (Eds.) The SAGE Handbook of Sociology (pp. 405-422). New York: SAGE Publications.

Wells, Y., Foreman, P., Gething, L. and Petralia, W. (2004). Nurses' Attitudes Toward Aging and Older Adults - examining attitudes and practices among health services providers in Australia. Journal of Gerontological Nursing, 30, 5-13.

Zimmerman, S., Dobbs, D., Roth, E.G., Goldman, S., Peeples, A.D. and Wallace, B. (2014). Promoting and Protecting Against Stigma in Assisted Living and Nursing Homes. The Gerontologist, 00, 1-13. doi:10.1093/geront/gnu058 